\title{
Hermandades de Semana Santa y redes sociales. Las nuevas tecnologías al servicio de la Información Cofrade
}

\author{
Semana Santa's Fraternity and Social Networks. New \\ technologies put to the service of the Cofrade's information
}

\author{
ALONSO GONZÁLEZ, Marián \\ Universidad de Sevilla (España) \\ malonsog@us.es \\ Recibido: 10 de junio de 2015 \\ Aceptado y Publicado: 18 de julio de 2015
}

\begin{abstract}
Resumen
Las herramientas derivadas de la Web 2.0 se han convertido en canales imprescindibles en las estrategias comunicativas de las empresas, pero también de organizaciones de diversa índole. Este es el caso de las Hermandades de Semana Santa de Sevilla, las cuales se enfrentan al reto de interactuar con el usuario, generar una comunidad de marca, incrementar su notoriedad y reforzar su posicionamiento comunicativo de cara a los medios de comunicación. La presente investigación pretende analizar el uso que hacen las Hermandades de los medios sociales a fin de establecer un espacio comunicativo propio en el que las nuevas tecnologías se ponen al servicio de la información Cofrade. Los resultados desvelan que han conseguido mejorar su comunicación tanto a nivel interno como de cara a los medios de comunicación, los cuales utilizan estas plataformas a modo de fuentes informativas, pese a que su valor como tal es relativo por incipiente y novedoso.
\end{abstract}

\section{Abstract}

The tools derived from the Web 2.0 have turned into essential channels to put across company strategy, as well as being so relevant in of organizations of diverse nature. Such is the case of Semana Santa's Fraternity of Seville, which has to address the challenge of interacting with users to generate a branded community in order to increase their reputation and reinforce their message position towards the media. The aim of this research attempts to analyse how the Fraternity make use of social media in order to establish a communicative space in which the new technologies put to the service of the Cofrade's information. The 
results show that they've improved their internal communication along with the information they offer to the media, who use them as information sources, although their value is relative on account of being incipient and innovative.

Palabras clave: Redes sociales; Web 2.0; Semana Santa; Sevilla; Hermandades. Keywords: Social Networks; Web 2.0; Seville; Semana Santa; Fraternity.

\section{Introducción}

Las redes sociales son una herramienta rápida y útil para divulgar noticias de gran relevancia mundial, de forma que su inmediatez y capacidad para traspasar fronteras informativas las convierten en el mejor vehículo de comunicación del que actualmente disponemos. Su gran velocidad en la difusión comunicativa es precisamente la cualidad que ha propiciado que las herramientas derivadas de la Web 2.0 permitan al receptor dejar de tener un rol de mero consumidor de contenidos para convertirse en un participante activo de los mismos.

La Web 2.0 supone un cambio en el paradigma comunicativo ya que el usuario de la Red pasa de ser un consumidor de contenidos a participar en el proceso de construcción y elaboración de los mismos, al tiempo que los medios que funcionan sobre este modelo participativo se convierten en rápidas plataformas de difusión de la información.

La presente investigación parte de la afirmación de que la comunicación institucional es un intercambio planificado de mensajes entre cualquier organización y sus grupos de interés, tanto internos como externos (Farias Batle, 2000: 65). En base a esta definición, que se basa en el triángulo de la comunicación empresarial e institucional, se establece que cualquier organización tiene la necesidad de comunicarse con sus públicos objetivos, emitiendo y recibiendo mensajes de manera planificada para conseguir que estos tengan una imagen positiva de la institución y creando, por ende, una cultura institucional.

Dentro de este contexto, las Hermandades de Semana Santa, al igual que otras muchas organizaciones aconfesionales, sienten la necesidad de comunicarse con lo que podríamos denominar su público objetivo, el cual estaría conformado a nivel interno por sus hermanos y a nivel externo por los medios de comunicación que, en una ciudad como Sevilla, otorgan a la Información Cofrade un lugar destacado dentro de su política comunicativa, sobre todo durante el periodo de Cuaresma y de forma especialmente relevante durante la Semana Santa. 


\subsection{Web social e identidades digitales}

Acuñado en 2003 por Tim O'Reilly, el concepto Web 2.0 hace referencia al fenómeno social surgido a partir del desarrollo de diversas aplicaciones en Internet que permiten a los usuarios interactuar y colaborar entre sí como creadores de contenidos. No obstante, apenas una década después su propio creador aseguraba que la idea estaba obsoleta y otras muchas voces comienzan a referirse a una etapa 3.0, cuyo objetivo, como afirman Sánchez González y García Estévez (2010: 379), es aportar un valor añadido a la información, "haciéndola más inteligente mediante ontologías o metadatos semánticos" e incluso una Web 4.0, lo que O'Reilly y Batelle (2009: 5) denominan Web Squared que sería aquella que "une la inteligencia de los ciudadanos y tecnologías como el filtrado, la inteligencia colectiva o la realidad aumentada para crear una web 2.0 multiplicada".

En este mismo sentido, Brian Solis explica que:

"la Information Shadow (la información de los objetos reales en el ciberespacio) y el Internet de las cosas (objetos identificados y capaces de conectarse e intercambiar información) hacen que la Web sea cada vez más inteligente, más rápida, más personalizada y más móvil" (2011: 32)

De forma que los medios sociales democratizan la información y cambian por completo la forma en que empresas y organizaciones se comunican con sus clientes y la forma en que los clientes influyen en las decisiones de amigos y conocidos.

Plataformas como Twitter, YouTube, Facebook, etc., han hecho posible que cualquier persona pueda conectar con otros usuarios, compartir intereses y crear comunidades que van modelando la percepción que tenemos de las marcas, y esta mayor participación hace que la web no crezca aritméticamente, sino exponencialmente. Dentro de este contexto de evolución imparable, las redes sociales aumentarán su poder en el futuro hasta el punto de desplazar, incluso, al resto de medios de comunicación (Fernández y Paniagua, 2014: 5), de hecho, en esta misma línea, el propio O'Reilly (2011) considera que Facebook se está convirtiendo en una suerte de sistema operativo social que está transformando Internet en estos momentos y que crea comunidad.

Esta cualidad social de las redes provoca que numerosas organizaciones y asociaciones, entre las que se encuentran las Hermandades de Penitencia de Semana Santa, intensifiquen su presencia en el ecosistema digital, al tiempo que planifiquen y desarrollen estrategias de comunicación en red que contemplen el 
uso de determinadas herramientas online (fundamentalmente Twitter, Facebook y YouTube), como fórmula que les permita estar cerca de sus públicos objetivos.

A todo ello ha contribuido de manera notable el uso extensivo de dispositivos móviles, especialmente tablets y smartphones, los cuales permiten estar conectados a cualquier hora y en cualquier lugar. De hecho, un reciente informe de la Fundación Telefónica (2015) afirma que España ha consolidado su liderazgo dentro de los países más relevantes de la Unión Europea en penetración de smartphones, con un "81\% de teléfonos inteligentes sobre el total de móviles, lo que supone diez puntos por encima de la media". Por su parte, la tablet, como dispositivo de acceso, dobla su penetración frente al 2011 con un 14\%. (AIMC: 2014)

26,2 millones de españoles (1,45 millones más que en 2013) se conectaron a Internet durante el pasado año, de ellos el 78,7\% navegó todos los días, porcentaje que se incrementó hasta el $88,9 \%$ en el caso de los jóvenes entre 16 y 24 años. Por su parte, el uso de las redes sociales aumentó tres puntos, hasta el $67,1 \%$, gracias al crecimiento experimentado en la franja de edad comprendida entre 45 y 54 años, que pasa del 43,5 en 2013 al 52,3 por cien en 2014.

Otros datos significativos que se desprenden de este estudio es que tres de cada cuatro internautas $(76,9 \%)$ utiliza la Red con fines comunicativos, cifra que llega al $95,6 \%$ en el segmento comprendido entre los 20 y 24 años. Asimismo, llama la atención el alto nivel de participación de los internautas en la creación de contenidos de las webs. De hecho, el $58 \%$ sube fotos, el $40 \%$ colabora con textos, el $68 \%$ lo hace con contenidos multimedia, el $45,6 \%$ ve, escucha y lee contenidos sin descargarlos y sin comentarlos o etiquetarlos, mientras que el $32,5 \%$ etiqueta y añade comentarios a los contenidos. A todo ello ha contribuido el uso generalizado de YouTube y las nuevas fórmulas de participación ciudadanas que los diarios online han puesto en uso.

Dentro de este contexto, las redes sociales, principalmente Facebook y Twitter, se erigen en herramientas que permiten modificar los procesos de creación, edición y distribución de contenidos de todo tipo, hasta el punto de ser uno de los ejes vertebradores del consumo digital en España, como evidencia el hecho que la red de microblogging haya experimentado un crecimiento del $600 \%$ en el último año en nuestro país.

Pese a ese incremento espectacular que hace de España el segundo país europeo y el octavo a nivel mundial con el mayor número de usuarios activos en Twitter, su nivel de penetración tan sólo alcanza el 12\% del espacio social digital, un marco que lidera de forma imbatible Facebook gracias a una combinación de 
intereses personales, profesionales y de contenido. La red social creada por Mark Zuckerberg posee 12 millones de usuarios españoles diarios y 18 millones de usuarios mensuales, lo que significa que el $58 \%$ de los usuarios españoles de Internet están en esta plataforma. Además, tiene 8,1 millones de usuarios móviles diarios y 13 millones de usuarios móviles mensuales, cifras que suponen el $32 \%$ de los usuarios móviles de España (TechCrunch, 2014).

\subsection{Semana Santa y Periodismo}

La Semana Santa constituye un acontecimiento que ha sido objeto de estudio desde numerosas perspectivas históricas y artísticas, pero sobre todo desde el ámbito antropológico ya que es consecuencia de tradiciones que se remontan hasta la época medieval y forman parte del acervo cultural español.

Considerada Fiesta de Interés Turístico Internacional, la Semana Santa en Sevilla es un fenómeno de carácter sociocultural, turístico y económico de gran importancia que se vive durante todo el año, ya que las Hermandades trabajan día a día en tres pilares fundamentales: formación, culto y caridad.

Aunque durante la Edad Media ya existieron Cofradías, no es hasta el siglo XVI cuando se consolidan las Hermandades de Pasión o Penitencia como asociaciones que veneran la pasión y muerte de Cristo y le rinden culto con una salida procesional.

En sus comienzos, las Cofradías sevillanas hacían Estación de Penitencia a iglesias o conventos cercanos a su templo, sin embargo, en 1604 se estableció la obligación de que todas las Cofradías tuvieran que acudir a la Catedral en su recorrido. Desde entonces, se denomina Carrera Oficial al itinerario común que deben realizar todas las Hermandades en su trayecto hacia la Catedral y que, marcado por el Consejo de Hermandades y Cofradías de Sevilla, comienza en la plaza de La Campana. El orden establecido en el paso de las Cofradías por la Carrera Oficial es el inverso a su antigüedad, excepto en la Madrugada, cuando se realiza en sentido contrario.

En la ciudad de Sevilla procesionan desde el siglo XVI las Cofradías el Domingo de Ramos, el Miércoles, el Jueves y el Viernes Santo, no será hasta el siglo XIX cuando se instaure el Martes Santo y en el siglo XX el Lunes Santo y el Sábado Santo. En la actualidad, desde el Domingo de Ramos al Domingo de Resurrección un total de 61 Cofradías realizan su recorrido por las calles de la capital hispalense y 11 más lo hacen en los dos días previos, Viernes de Dolores y Sábado de Pasión. No obstante, durante todo el año las Hermandades cuentan 
con numerosos cultos internos a sus titulares, tal es el caso de novenas, septenarios, quinarios, triduos y besamanos.

El Consejo General de Hermandades y Cofradías de Sevilla es el órgano encargado de la regulación del conjunto de procesiones de la Semana Santa, y como tal agiliza trámites y acuerdos con las instituciones oficiales, al tiempo que controla los horarios de paso por la Carrera Oficial. Sus miembros son elegidos cada cuatro años por los Hermanos Mayores de las distintas Hermandades.

Según este Consejo General de Hermandades y Cofradías de Sevilla, la cofradía de Semana Santa o de Pasión puede definirse como:

"la asociación de fieles, en la mayoría de los casos exclusivamente laicos, que une dos elementos: en primer lugar la contemplación de la Pasión y Muerte de Cristo y, en segundo lugar, la imitación de los dolores de Cristo en su Pasión y Muerte por medio de una penitencia pública que se concreta en la autoflagelación (y se pudo concretar también en otros tipos de penitencia) llevada a cabo durante la realización de la procesión o "Estación de Penitencia" efectuada en uno de los días de la Semana Santa". (Hermandades de Sevilla, 2014).

Asimismo, pueden distinguirse tres tipos diferentes de Cofradías, las del Crucificado, grupo constituido por las que integran la Santa Vera Cruz y que se ven influenciadas y unidas a las de la Sangre de Cristo; un segundo grupo conformado por aquellas que poseen un Jesús Nazareno o Jesús llevando la Cruz a cuestas (dentro de este grupo estarían también las Cofradías que giran en torno a la Sagrada Columna y Azotes, la Coronación de Espinas, Cristo de la Sentencia, Ecce Homo o Jesús presentado al pueblo y el Cristo de la Humildad y Paciencia) y por último las relacionadas con el Santo Entierro y el Resucitado. En este último grupo también se integran aquellas Cofradías autónomas de Nuestra Señora de los Dolores, de las Angustias y de la Soledad. (Sampedro, 2011)

Debido a la importancia que Sevilla otorga a su Semana Santa y sus Hermandades y a la necesidad que la población tiene de estar bien informada sobre todo cuanto rodea al mundo cofrade, desde lo puramente religioso al desfile de bandas procesionales, los medios de comunicación sevillanos dedican un espacio fijo a este tipo de informaciones dentro de la sección de Religión, un espacio que se va haciendo cada vez más profuso a medida que avanza la Cuaresma y que llega a convertirse en epicentro de la actualidad durante la Semana de Pasión, llegando, incluso, a eclipsar al resto de noticias, las cuales quedan relegadas a breves o faldones. 
Desde el punto de vista periodístico existe un subgénero cofrade que tiene entidad propia, tal y como ocurre con el Periodismo taurino, cinéfilo o teatral, ya que exige de vastos conocimientos históricos y culturales, de costumbres locales y nacionales. Este subgénero es cultivado por igual en prensa, radio y televisión. De hecho, al igual que las páginas de los diarios se llenan de imágenes y crónicas de las salidas procesionales, los medios audiovisuales poseen programas específicos destinados a la difusión de todas las novedades cofrades.

Así pues, en radio encontramos programas míticos como "Cruz de Guía", el magazine dedicado a la actualidad cofrade que con el inconfundible estilo de Paco García, todos los lunes de 21 a 22 horas, llena de marchas procesionales Radio Sevilla (Cadena Ser) y el que, sin lugar a dudas, es el programa por antonomasia de la Semana Santa en Sevilla, "El Llamador" de Canal Sur, que lleva en antena veinticinco años, pues se inicia con las transmisiones de la cadena de radio autonómica.

Bajo la dirección de Francisco José López de Paz, con José Manuel de la Linde, Antonio Cattoni y Charo Padilla, "El Llamador" dedica desde el 1 de noviembre una hora semanal al análisis y repaso de la actualidad que generan las Hermandades sevillanas, sin embargo, es durante la Semana Grande cuando intensifican sus emisiones, de forma que el programa llega a emitir más de cien horas de información cofrade. Las transmisiones comienzan cuando sale la primera Hermandad y concluyen con la entrada de la última, entre medias, además de ofrecer los sonidos y la narración del paso de las Cofradías, aporta información de servicio público y utilidad.

No podemos olvidar, Radio La Saeta (http://www.radiolasaeta.es), una emisora temática online 24 horas cuyo único objetivo es difundir y llevar a todos los lugares del mundo la Semana Santa, su cultura, su música y el sentimiento cofrade.

A nivel televisivo merece la pena reseñar las retransmisiones realizadas por Tele Sevilla. En colaboración con Abc de Sevilla, la cadena ha realizado conexiones en directo a través de Internet desde La Campana (punto de inicio de la Carrera Oficial) y el entorno de la Plaza del Salvador. Pasión en Sevilla, el portal de Cofradías de $\mathrm{ABC}$, ha permitido el seguimiento en tiempo real del desfile de todas las Hermandades, con comentarios en directo, vídeos y fotografías, a través del ordenador, IPad y smartphone gracias a un acuerdo con la televisión local.

También un extenso equipo de profesionales y periodistas expertos en Cofradías ha hecho posible que El Correo TV haya ofrecido una amplia cobertura de la semana más universal que se inicia el Viernes de Dolores por la tarde con la 
salida a la calle de los primeros nazarenos en los barrios de Sevilla. El operativo, que ha podido seguirse desde cualquier parte del mundo a través del streaming en la web de El Correo de Andalucía (http://www.elcorreoweb.es), ha contado, además, con dos sets en el centro de Sevilla, uno en el Ayuntamiento y otro en las Setas de la Encarnación, en los que se ha entrevistado a los protagonistas de cada jornada.

El seguimiento vía Internet de la Semana Santa en Sevilla no es un fenómeno nuevo y prueba de ello es que hace ya siete años, en 2007, el Ayuntamiento de Sevilla y el Consorcio de Turismo crearon una plataforma turística a través de la cual era posible seguir el devenir de esta semana grande hispalense.

Esta iniciativa surgió con el propósito de aprovechar la potente herramienta que supone Internet, de forma que la plataforma de televisión turística IP combinaba la riqueza visual de la emisión televisiva con la inexistencia de fronteras y la interacción que proporciona la Red, pudiendo adaptar la emisión a cada usuario (Fresneda, 2008). Esta televisión se visionó a través del site http://www.turismosevilla.tv, al tiempo que se hizo accesible desde un enlace en la página web del Consorcio de Turismo.

A nivel digital merece la pena reseñar los sitios web de los diarios Abc de Sevilla, "Pasión en Sevilla" (http://sevilla.abc.es/pasionensevilla/), Diario de Sevilla (http://www.diariodesevilla.es/cofradias), El Correo de Andalucía (http://elcorreoweb.es/semanasanta), el blog de José Gómez Páñas "Cuerpo de Ciriales" publicado en dicho periódico todos los sábados (http://blogs.elcorreoweb.es/cuerpodeciriales), y la web Arte Sacro (http://www.artesacro.org), el portal web de referencia sobre las noticias relacionadas con el mundo cofrade.

\subsection{Semana Santa y Universo 2.0}

Que el Universo 2.0 también ha alcanzado a la Semana Santa es un hecho innegable, y pese a que siempre primará una condición por encima de todo ello: que la modernidad no interfiera en la estética de una expresión que cuenta con varios siglos de vida y tradición, las nuevas aplicaciones para móviles y tablets, las redes sociales para cofrades, las procesiones en streaming... hacen que las nuevas tecnologías acerquen la Pasión por las vías más insospechadas.

Una simple búsqueda en Google pone de manifiesto la existencia de más de tres millones de páginas webs dedicadas a la Semana Santa en toda España, de hecho, prácticamente cada ciudad española cuenta con su propio espacio virtual 
dedicado a ella. Una de las pioneras es www.semanasantapalencia.com, de la Hermandad de Cofradías, la cual también ha creado una radio digital denominada El Cimbalillo Cofrade, o www.tuSemanaSanta.com que surgida en 2008 e inicialmente centrada en las celebraciones en Cáceres, también ofrece noticias y datos de otras provincias españolas.

Las redes sociales también se convierten en la plataforma idónea para compartir inquietudes, anécdotas y consejos. Así, junto a Facebook y Twitter encontramos otras redes específicas y únicas para los amantes de la Semana Santa como SoyCofrade, que permite a sus 400 usuarios estar al día de las distintas actividades organizadas por las Hermandades. Creada por Alberto Jiménez, su funcionamiento es muy sencillo y ofrece tres tipos de cuenta, una privada, otra para Cofradías y una última para bandas de música y cornetas, además, sus usuarios puede compartir experiencias personales en un máximo de 300 caracteres y linkar cualquier tipo de enlace.

También existen espacios virtuales específicamente desarrollados para este tipo de contactos, tal es el caso de la web www.Pasionensevilla.tv, de Abc de Sevilla, en la que los usuarios pueden colgar fotos y comentar sus experiencias, además de mantenerse informados sobre la Semana Santa hispalense.

La estrecha relación existente entre las redes sociales y la Semana Santa ha dado como fruto la publicación Cofrades 2.0, la primera revista que analiza la repercusión que la Semana Santa tiene en las redes sociales y plantea temas de interés para los tuiteros.

Junto a la profusa información que sobre la Semana Santa nos ofrecen los medios de comunicación tradicionales y la progresiva incorporación de las Hermandades y Cofradías de Sevilla al universo web, Internet alberga numerosas aplicaciones dedicadas a la Semana Santa, así pues, sólo en el Play Store de Android encontramos 400 programas dedicados a la misma y que abarcan desde libros temáticos a marchas, saetas y juegos, tal es el caso del "Trivial Sevilla Cofrade" que nos permite evaluar nuestros conocimientos sobre la historia y las curiosidades de las procesiones sevillanas.

El bazar digital de los usuarios de Apple también ofrece podcasts con rezos, procesiones o recopilatorios de sonidos de la Semana Santa, no obstante, las aplicaciones más descargadas durante la pasada Semana de Pasión de 2014 han sido aquellas que informan del recorrido de las procesiones y las previsiones meteorológicas. Entre ellas ocupa un lugar destacado iLlamador que, elaborada por el equipo del programa "El Llamador" de Canal Sur, podía bajarse de forma 
gratuita a través de la siguiente dirección web: http://www.semanasantaentumovil.com/llamador

Con más de 86.785 .981 consultas durante los 16 días, 9 horas, 30 minutos y 58 segundos que ha estado activo, iLlamador ha sido la referencia informativa de la Semana Santa de 2014 y para ello ha ofrecido una completa descripción de las Hermandades, así como sus recorridos con realidad aumentada por geolocalización, al tiempo que ha permitido conocer el tiempo exacto de espera para la llegada de las Hermandades hasta el lugar concreto en el que se encontraba el usuario, el tiempo atmosférico, los tweets relacionados y los puntos y teléfonos de interés necesarios para disfrutar de la Semana de Pasión en la capital andaluza.

Después de tres años de experiencia, esta aplicación, que incluye además una galería multimedia de fotos y audios, permite escuchar el programa de Canal Sur Radio en directo, así como acceder al GPS, teléfonos de emergencia, actualizaciones del Twitter de Canal Sur e información corporativa de la cadena; ha registrado 120.174 descargas, duplicando las del año anterior, de las que de las que 87.095 han sido desde Android a través de la plataforma Google Play y 13.029 de iPhone desde el Apple Store, donde ha ocupado la cima de descargas. (Canal Sur, 2014).

De reciente creación, ya que fue estrenada la pasada Semana Santa, encontramos la Agenda Cofrade Cirineo Sevilla, una aplicación que según sus propios creadores "es un nuevo medio de difusión y fomento de la religiosidad popular en Sevilla y su mundo cofrade", y que es la primera App en Sevilla con cobertura anual de la Cuaresma, Carrera Oficial, Geolocalización de cada punto del cortejo procesional, salidas extraordinarias, Glorias, seguimiento de la peregrinación de las Hermandades filiales a la Virgen del Rocío, difusión de las novedades y noticias de las Hermandades y Cofradías, guía de todos los templos y sedes canónicas, cultos y misas de la vida interna de las Cofradías y una Agenda Cofrade con notificaciones y avisos a los usuarios.

Creada por la Asociación Cirineo, esta aplicación ha contado con el patrocinio de Tussam, 8TV Andalucía y Cope Sevilla, así como con la colaboración del MAEV (Máster en Artes del Espectáculo en Vivo) de la Universidad de Sevilla.

Otras aplicaciones similares que podemos encontrar es la potente iCofrade, disponible para Málaga y Córdoba, y que abarca un total de 14 ciudades españolas. Entre sus ventajas destacan la fácil accesibilidad que otorga su diseño multiplataforma, la constante actualización de sus contenidos y la posibilidad de enlazar con las redes sociales de las Hermandades. 


\section{Metodología}

Las formas de comunicación han cambiado. En la sociedad actual, nuevos parámetros y métodos se han impuesto principalmente a consecuencia de las nuevas tecnologías y su extenso mundo. Las Hermandades y Cofradías de Semana Santa de Sevilla no han sido una excepción y en los últimos años han debido de amoldarse a vivir en lo real y en lo digital utilizando nuevas herramientas como la web y las redes sociales, de hecho la incorporación y adaptación de las Hermandades a los nuevos tiempos y avances tecnológicos se hace patente al observar a sus nazarenos provistos de Gps y utilizando mensajería Sms, Whatssap e incluso las redes sociales Facebook, Tuenti y Twitter.

El principal objetivo de esta investigación es estudiar la presencia de las Hermandades de la Semana Santa de Sevilla en las redes sociales a fin de establecer cómo estas asociaciones utilizan las herramientas derivadas de la Web 2.0 y sus potencialidades con fines comunicativos hacia todos sus usuarios, tanto internos, es el caso de sus hermanos, como externos, entre los que se encuentran, indudablemente, los medios de comunicación hispalenses, los cuales no son ajenos a dichas herramientas y, en ocasiones, las utilizan como fuentes informativas, haciéndose eco de las noticias publicadas por las mismas para enriquecer su discurso noticioso.

Junto al objetivo general nos marcamos otros objetivos secundarios que detallamos a continuación:

1. Evaluar en qué medida el uso de las redes sociales Twitter y Facebook contribuye a la mejora de la comunicación a través de un análisis de contenido de las cuentas de las Hermandades objeto de nuestro estudio.

2. Conocer el nivel de actividad, participación y ritmo de publicación a través de sus perfiles durante el periodo de Cuaresma y durante la Semana Santa de 2014.

3. Determinar el flujo comunicativo que establecen con los ciudadanos y el nivel de interactividad.

4. Intentar determinar el uso que hacen de las herramientas derivadas de la Web 2.0, su conocimiento de las mismas y mostrar si su utilización puede contribuir a acercar la información cofrade a la ciudadanía y a los medios de comunicación.

Las hipótesis de partida son: 
1. Las Hermandades de Semana Santa utilizan las redes sociales para generar una comunidad de marca y para mejorar de forma sustancial la manera en que se comunican con sus hermanos y la sociedad en general.

2. Gracias a las herramientas derivadas de la Web 2.0 las Hermandades de Semana Santa refuerzan su posicionamiento comunicativo de cara a los medios de comunicación.

El método de trabajo elegido para realizar una aproximación al problema de investigación planteado, y en correspondencia con la naturaleza del objeto a investigar, sigue una perspectiva metodológica mixta en la cual se completan los enfoques cuantitativo y cualitativo.

Esta articulación, cuyas ventajas han sido destacadas por distintos autores (Creswell y Plano, 2011) en respuesta a la oposición dicotómica entre ambos planteamientos, permite una comprensión del problema de investigación en el cual se articula la utilización de estadísticas y la medición de determinados fenómenos, propios de lo cuantitativo, con la exploración en profundidad de la problemática examinada y la extracción y comprensión de los significados vinculados las mismas, característico de lo cualitativo.

Así pues, junto a la imprescindible revisión bibliográfica que toda investigación requiere, para el seguimiento de este estudio hemos realizado un trabajo de carácter exploratorio de rastreo de la actividad comunicativa desarrollada por las Hermandades que mayor número de seguidores poseen en Twitter y Facebook, ya que son las dos redes sociales más generalistas y populares en todo el mundo. De hecho, según datos de enero de 2014, Facebook posee mil millones de usuarios activos que comparten cada día un total de 2,5 millones de piezas de contenidos, mientras que Twitter registra 560 millones de usuarios activos que publican un total de 5.700 tweets por segundo. (Mediabistro: 2014).

En España, según el medidor externo, Adexa.com, Facebook ocupa el tercer lugar en el ranking de webs con mayor audiencia del planeta, superada únicamente por Google.es y .com, mientras que Twitter ocupa el sexto lugar, por detrás de YouTube y Live.com.

Cada red social tiene sus propias pautas y normas de comportamiento, pero en líneas generales tanto en Facebook como en Twitter cada usuario establece un espacio virtual de comunicación interpersonal y colectivo que no tiene por qué coincidir temporalmente en la acción, ofrece un punto virtual de reunión en el que la invitación a entrar es permanente y en el que el contenido llega al usuario sin necesidad de que este lo busque, de forma que adquiere un importante matiz de proactividad. 
Otras características comunes que presentan ambas redes sociales y que hemos considerado como clave a la hora de elegirlas es una vigencia limitada del mensaje y una comunicación dialógica cuyas aportaciones se ciñen a los criterios de brevedad y concisión, y en el que prima la jerarquización de contenidos para que el receptor lo tenga todo a simple vista.

El tiempo de estudio lo hemos establecido del 5 de marzo al 20 de abril, es decir el periodo comprendido entre el Miércoles de Ceniza y el Domingo de Resurrección a fin de poder analizar la comunicación que las Hermandades realizan durante el tiempo de la Cuaresma (5 de marzo-12 de abril) y la Semana Santa, propiamente dicha, que durante 2014 se ha desarrollado del 13 al 20 de abril.

De igual forma, hemos utilizado el análisis de contenido, una de las técnicas cualitativas más reconocidas y que responde a la sintetización de un enfoque específico empleado con frecuencia en casi todas las áreas de investigación sobre los medios de comunicación. Este es un método bastante popular y eficaz a la hora de analizar los contenidos mediáticos a través de aplicaciones concretas. Berelson (1952) destaca el carácter objetivo y sistemático de los datos recogidos a través de esta técnica. Esto permite "formular a partir de ciertos datos, inferencias reducibles y válidas que puedan aplicarse a su contexto". (Krippendorff, 1990: 23)

En este sentido, hemos establecido los parámetros 0 aspectos que considerábamos que se debían analizar o medir y que, entre otros, registran el tono del lenguaje (formal o informal) y los flujos de comunicación (ascendentes o descendentes) para señalar si es una comunicación entre iguales o jerárquica. Asimismo, hemos procedido a registrar si los mensajes eran de texto o incluían fotografías y vídeos, así como la frecuencia de actualización de los contenidos y de los comentarios y si la comunicación ejercida era unidireccional o bidireccional. Respecto a la visibilidad hemos pretendido analizar el número de fans o seguidores, los tweets y retweets generados, y el tipo de contenido publicado (temática de las publicaciones).

\section{Resultados}

Los resultados del estudio de campo según los objetivos fijados por la investigación giran en torno a dos ejes, por un lado el uso informativo interno al que destinan las Hermandades las noticias difundidas en las redes sociales y, por el otro, cómo los medios de comunicación usan esas publicaciones a modo de 
fuentes informativas. El análisis transversal de ambos nos permitirá obtener las conclusiones sobre el objeto de estudio.

\subsection{Hermandades y comunicación en redes sociales}

Las Hermandades de la Semana Santa de Sevilla se han incorporado a las redes sociales con objeto de mejorar de forma sustancial la manera en que se comunican con sus hermanos y la sociedad en general. Desde renovadas y modernas páginas web que permiten múltiples servicios, a boletines informativos digitales, las Cofradías se apuntan, sin dudarlo, al 2.0 y utilizan con excelentes resultados "las conocidas listas de distribución. (Parejo, 2012)

En este sentido, las corporaciones se valen del correo electrónico para comunicar actos, convocatorias o misas, un sistema que se ha revelado como eficaz a la par que barato y que les permite destinar todos sus recursos a las obras de caridad. De igual forma, sus webs corporativas se consolidan como una herramienta primordial de comunicación ya que junto a apartados destinados a la difusión de la historia, los fines y el patrimonio de la hermandad, la mayoría de ellas cuentan con espacios privados a través de los cuales los hermanos pueden realizar numerosas gestiones y disfrutar de múltiples servicios, entre ellos sacar la papeleta de sitio para la Estación de Penitencia, una iniciativa de la Hermandad de Santa Genoveva (www.santagenoveva.com).

La web de la Hermandad de la Macarena (www.hermandaddelamacarena.es) es una de las más completas y permite realizar donativos online, comprar recuerdos, disfrutar del canal de televisión Esperanza Macarena o realizar una visita virtual por la basílica y el museo de la corporación. Asimismo, y conscientes de la importancia que tiene estar comunicados en una sociedad cada vez más globalizada, la mayoría de las Hermandades cuentan con un boletín digital a través del cual difunden las noticias, cultos, convocatorias, calendarios, etc.

Según el Consejo General de Hermandades y Cofradías de la ciudad de Sevilla existen 69 Hermandades de Penitencia, de las cuales 9 salen entre el Viernes de Dolores y Sábado de Pasión. Las 60 restantes quedan repartidas de la siguiente manera: 8 el Domingo de Ramos, 9 Lunes Santo, 8 Martes Santo, 9 Miércoles Santo, 7 Jueves Santo, 6 Madrugá, 7 Viernes Santo, 5 Sábado Santo y 1 el Domingo de Resurrección.

Todas ellas, menos dos (Santísimo Cristo de la Corona y Divino Perdón) cuentan con presencia en la Red a través de una web propia o mediante un blog, tal el caso de El Carmen Doloroso, Padre Pío; Pasión y Muerte y San José Obrero. De igual forma, cada vez son más las Hermandades que apuestan por disponer de 
un espacio propio en las redes sociales de mayor impacto mediático, véase Twitter y Facebook.

El $65 \%$ de las Hermandades tienen perfil en Twitter, siendo la pionera La Candelaria en 2009. En el último año, las incorporaciones a esta red social han llegado al 12\%, pasando de 38 a las 45 actuales tras abrir su cuenta El Gran Poder el 21 de marzo de 2014 (Ver Gráfico 1 y 2).

Gráfico 1: Presencia de las Hermandades en Twitter

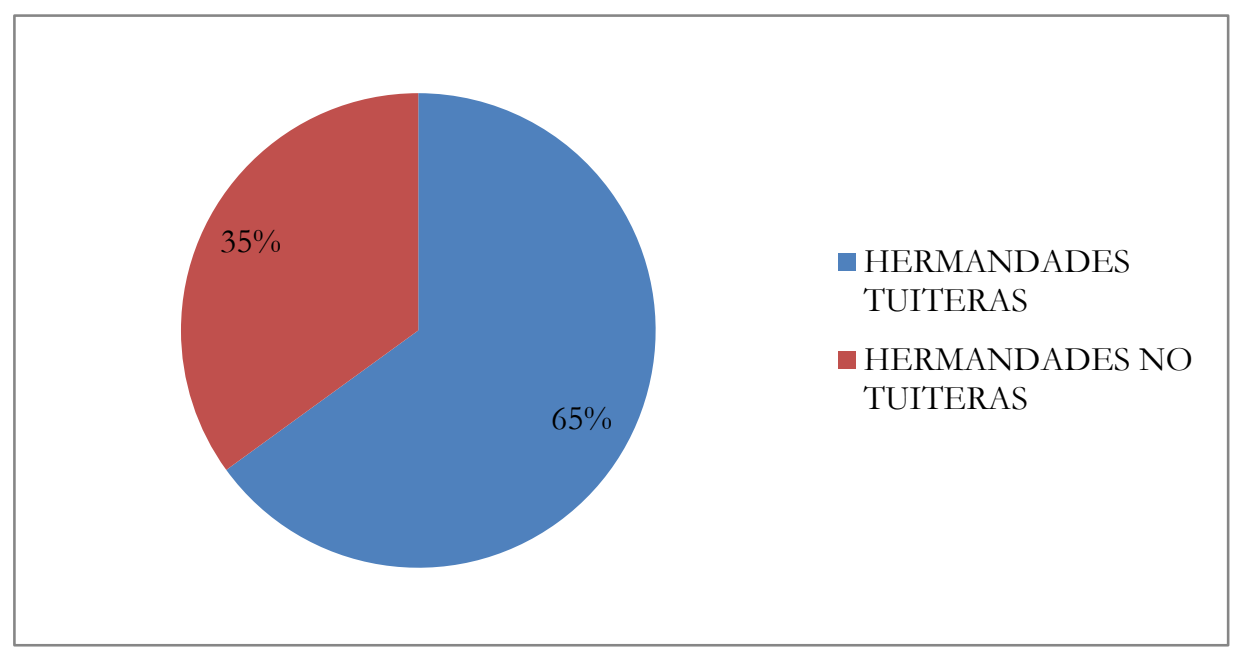

Fuente: Elaboración propia

Gráfico 2: Porcentaje de Hermandades presentes en Twitter en 2013 y 2014 


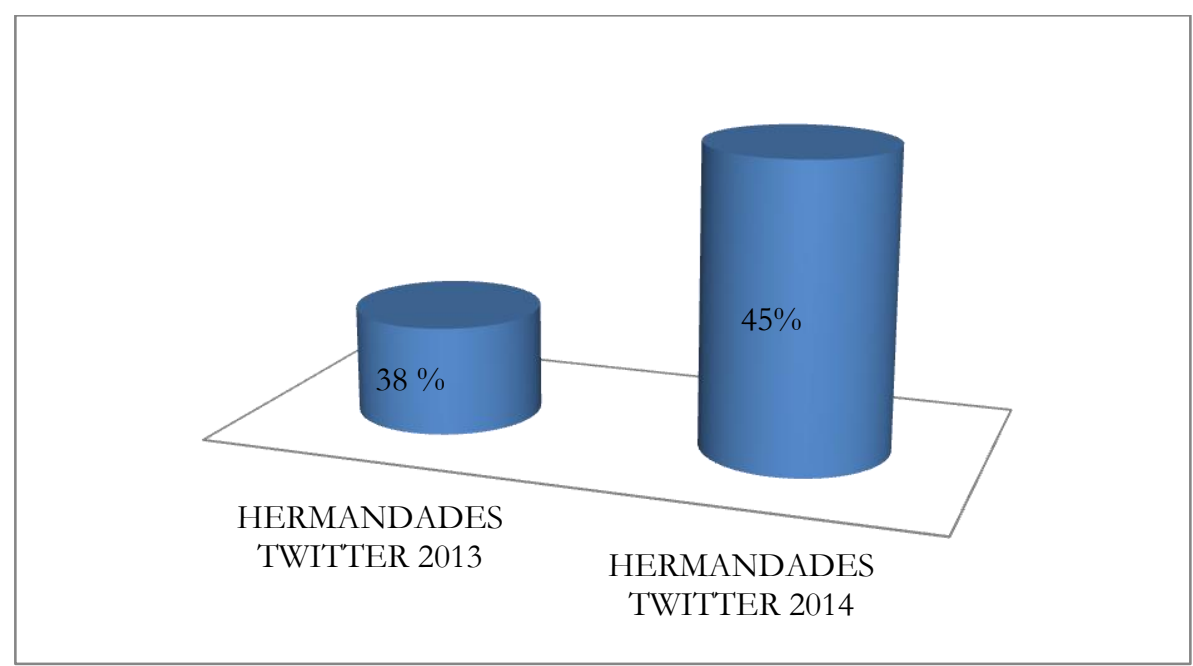

Fuente: Elaboración propia

Por jornadas, Miércoles Santo (89\%), Martes Santo y Domingo de Ramos, ambos con un $88 \%$, son los días en los que realizan su salida procesional la mayoría de Hermandades con una cuenta en Twitter. En el extremo contrario encontramos el Jueves Santo, con tan sólo un $29 \%$ de sus Hermandades presentes en dicha red social (Ver Tabla 1).

Tabla 1: Presencia de las Hermandades en Twitter por días

\begin{tabular}{|l|r|}
\hline PREVIO & $44 \%$ \\
\hline DOMINGO DE RAMOS & $88 \%$ \\
\hline LUNES SANTO & $67 \%$ \\
\hline MARTES SANTO & $88 \%$ \\
\hline MIÉRCOLES SANTO & $89 \%$ \\
\hline JUEVES SANTO & $29 \%$ \\
\hline MADRUGÁ & $67 \%$ \\
\hline VIERNES SANTO & $71 \%$ \\
\hline SÁBADO SANTO & $40 \%$ \\
\hline DOMINGO DE RESURRECCIÓN & $100 \%$ \\
\hline
\end{tabular}

Fuente: Elaboración propia

Atendiendo a la difusión e interactuación que poseen con sus públicos objetivos, Esperanza de Triana, La Macarena y El Cachorro son las Hermandades que un 
mayor número de followers tienen y que han experimentado un crecimiento exponencial durante el último año, llegando incluso a triplicar su número de seguidores.

Este incremento puede observarse en el siguiente cuadro donde establecemos un ranking con las diez Hermandades con mayor seguimiento y en el que se puede ver la evolución experimentada por la Hermandad de San Gonzalo que del puesto 10 sube al 5. También escalan posiciones San Benito y Santa Genoveva que estaban en los puestos 12 y 15, respectivamente, con 3.378 y 3.326 seguidores, cada una (Ver Tabla 2 y 3 ).

Tabla 2: Comparativa de Hermandades con más seguidores en Twitter, años

2013-14

\begin{tabular}{|c|c|c|c|}
\hline 2014 & & 2013 & \\
\hline HERMANDADES & SEGUIDORES & HERMANDADES & SEGUIDORES \\
\hline @EspDeTriana & 27.209 & @EspDeTriana & 11.186 \\
\hline @Hdad Macarena & 24.487 & @Hdad Macarena & 8.094 \\
\hline @HdadCachorro & 14.134 & @HdadCachorro & 4.815 \\
\hline @hdadlaestrella & 13.550 & @hdadlaestrella & 4.771 \\
\hline @HdadSanGonzalo & 12.621 & @HermandadPaz & 4.732 \\
\hline @HermandadPaz & 11.044 & @Hdad Amargura & 4.038 \\
\hline @LanzadaSevilla & 10.851 & @LanzadaSevilla & 3.997 \\
\hline @Hdad SanBenito & 10.781 & @DoloresdelCerro & 3.967 \\
\hline @Hdad Amargura & 10.042 & @HdadSanEsteban & 3.718 \\
\hline @hdadstagenoveva & 9.439 & @HdadSanGonzalo & 3.649 \\
\hline
\end{tabular}

Fuente: Elaboración propia

Tabla 3: Hermandades más seguidas en Twitter durante 2013 


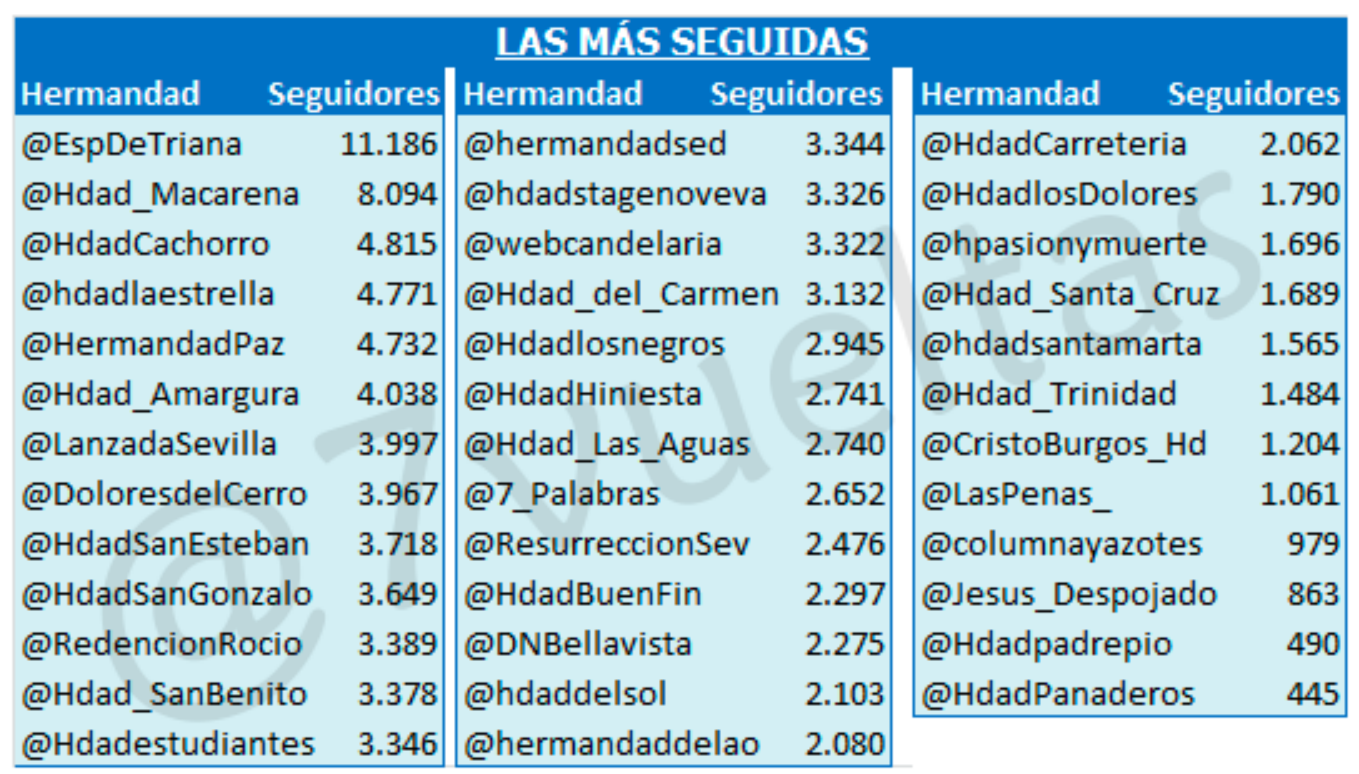

Fuente: Evonova (2013)

A nivel cuantitativo la frecuencia de publicación es bastante alta. Casi la totalidad de las Hermandades publica de uno a tres tweets diarios durante el periodo de Cuaresma, habiendo incluso algunas en las que esta cantidad llega a un promedio de diez por día, tal es el caso de La Macarena, con 116, San Gonzalo con $115 \mathrm{o}$ el Sol con 109 tweets publicados. En los dos siguientes gráficos podemos observar cuáles han sido las Hermandades más activas en Twitter durante las dos semanas previas a la Semana Santa (Ver Gráfico 3).

Gráfico 3: Tweets publicados durante la Cuaresma de 2014 


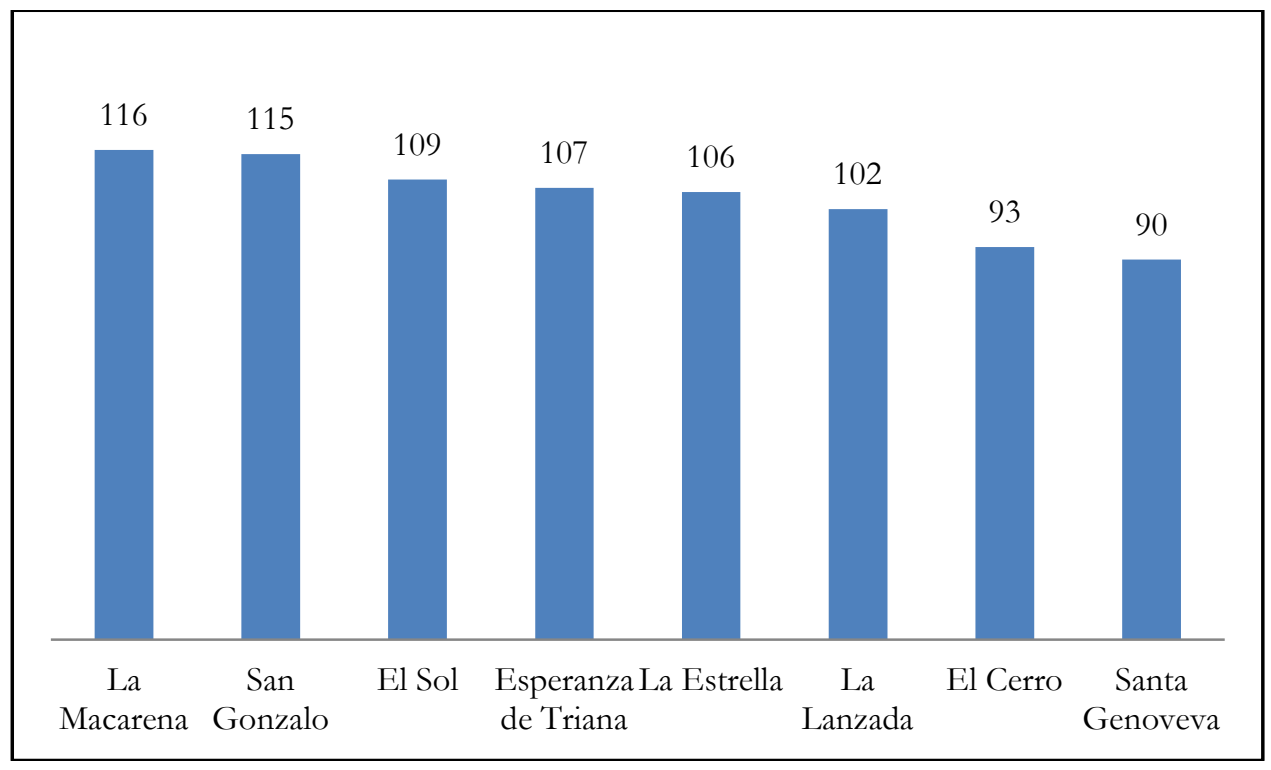

Fuente: Elaboración propia

Gráfico 4: Retweets generados durante la Cuaresma de 2014

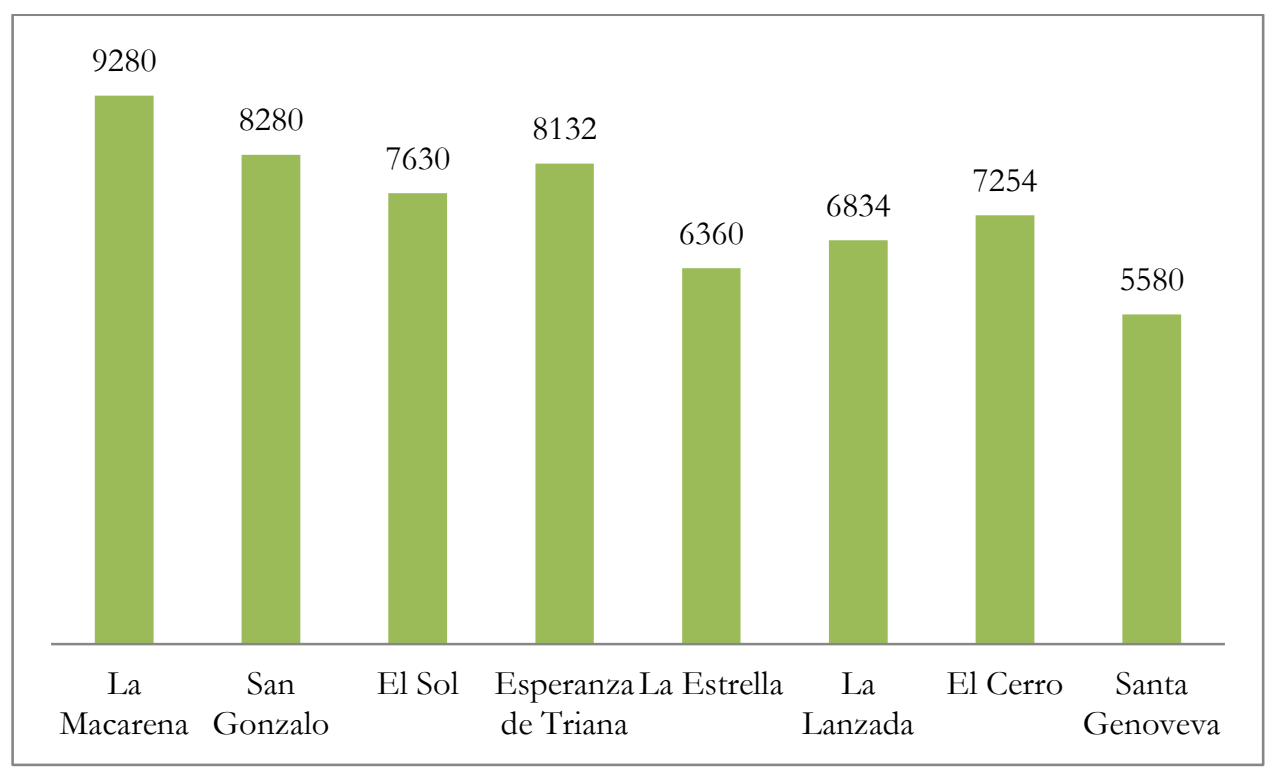

Fuente: Elaboración propia

A nivel cualitativo, el tono empleado en los tweets es bastante formal y el flujo comunicativo bidireccional, tal y como atestiguan los retweets y comentarios que generan las distintas entradas (Ver Gráfico 4) . Respecto a la temática, se pueden establecer seis hilos argumentales comunes para todas las Hermandades: 
Noticias (de la vida de Hermandad), Evangelios (incluye una agenda de las lecturas a realizar durante la semana), Agenda, Estación de Penitencia (incluye papeletas de sitio, horarios, normas y directrices), Talleres y actividades (dirigidos a los más jóvenes) y por último, Culto (Triduos, Novenas, besamanos, etc.).

En términos porcentuales, el grueso informativo, un 45\%, serían publicaciones dedicadas a Noticias, siguiéndole a bastante distancia Evangelios (17\%) y Cultos (16\%) (Ver Gráfico 5).

Junto a la función de notificación, la mayoría de las Hermandades (casi un $80 \%$ ) utiliza Twitter para retransmitir cultos, resolver dudas, retuitear fotos o responder a sus hermanos, de forma que podemos observar un elevado número de retweets, en torno a los 40 semanales, y con una temática muy diversa: fotografías, enlaces a informaciones con gran interés de difusión, referencias personales o simples comentarios.

De igual forma, observamos un nivel medio de hipertextualidad, ya que la mayoría de los enlaces a los que vinculan los tweets analizados eran sitios web y vídeos colgados en la plataforma YouTube.

Gráfico 5: Temática de los tweets publicados durante la Cuaresma de 2014 


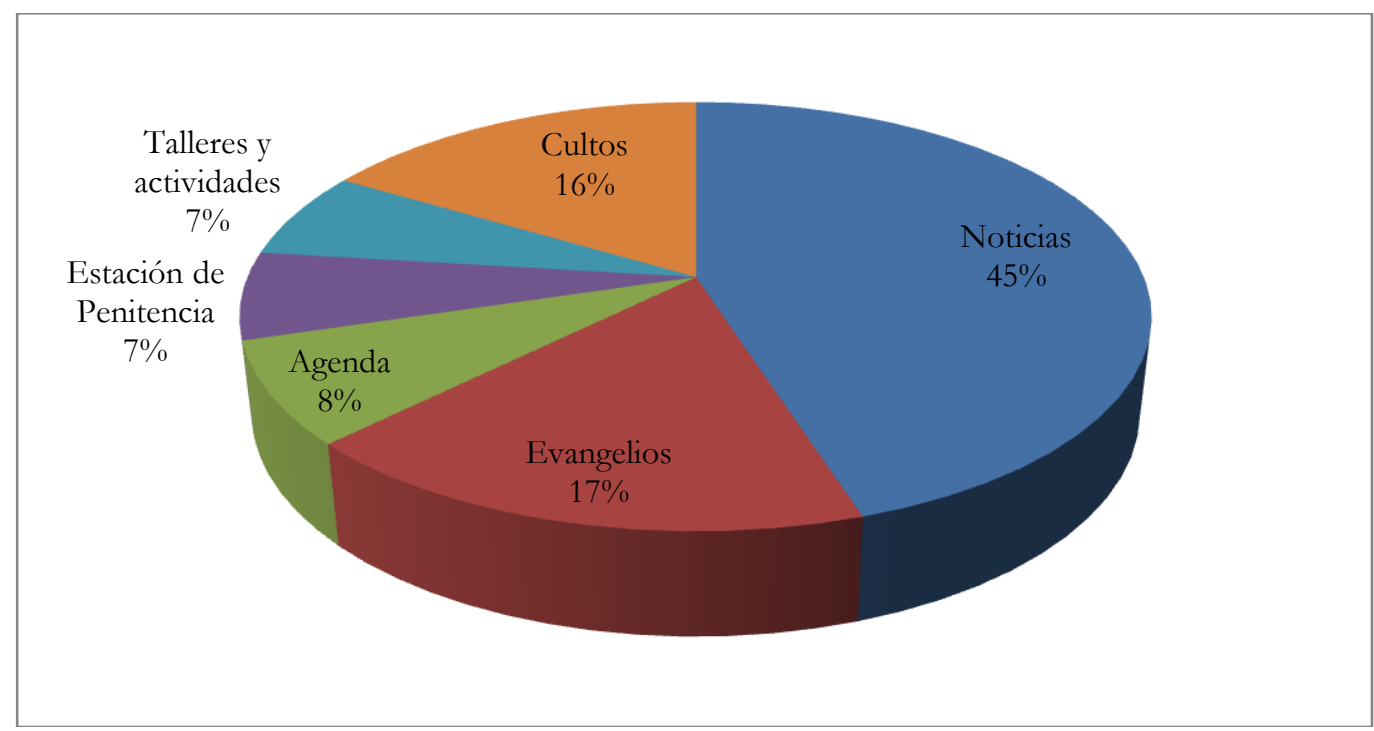

Fuente: Elaboración propia

Durante la Semana Santa de 2014, desarrollada entre los días 13 y 20 de abril, hemos observado una gran actividad comunicativa en Twitter, llegando, incluso, a aumentar ligeramente el número de publicaciones, las cuales se concentran de forma masiva (en torno al 90\%) en el día en que cada una de las Cofradías realiza su Estación de Penitencia. La temática ha versado en exclusiva sobre el día grande de la Hermandad, dedicándose un $10 \%$ de los tweets a desear suerte al resto de Cofradías que procesionan ese mismo día y a dar las gracias a todos los que han hecho posible celebrar el día grande de la Hermandad.

La Macarena, La Lanzada, La Estrella y El Cerro han sido las Hermandades que mayor actividad comunicativa han presentado, superando los 40 tweets, como puede observase en el Cuadro 9. De igual forma, el número de retweets se ha disparado en comparación con el periodo de Cuaresma, llegando a un sumatorio de 5.716 en la Hermandad de El Cerro, 4.463 en La Macarena y 3.820 en La Estrella (Ver Grafico 6 y 7 ).

Los mensajes presentan un lenguaje formal con flujos comunicativos bidireccionales que apunta a una comunicación entre iguales, asimismo, el $64 \%$ de los tweets contiene enlaces a fotos y vídeos, lo que se traduce en un nivel de hipertextualidad de las publicaciones de tipo medio. 
Gráfico 6: Tweets generados durante la Semana Santa de 2014

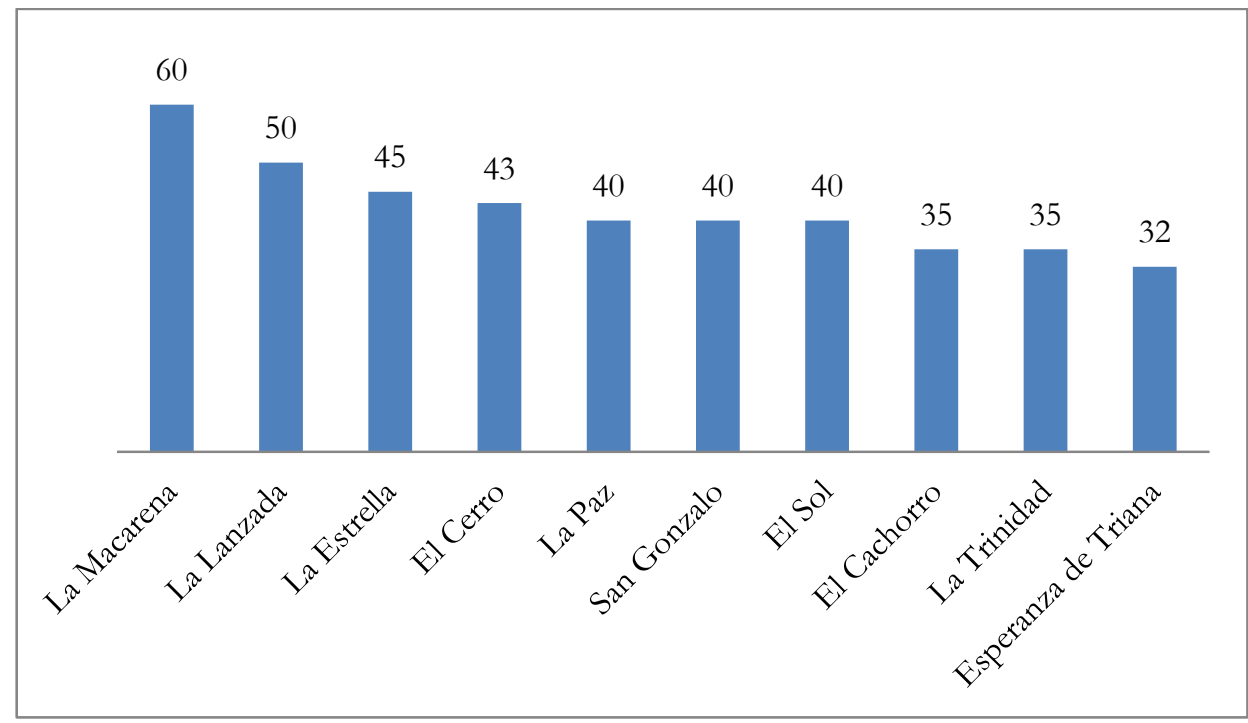

Fuente: Elaboración propia

Gráfico 7: Retweets generados durante la Semana Santa de 2014 


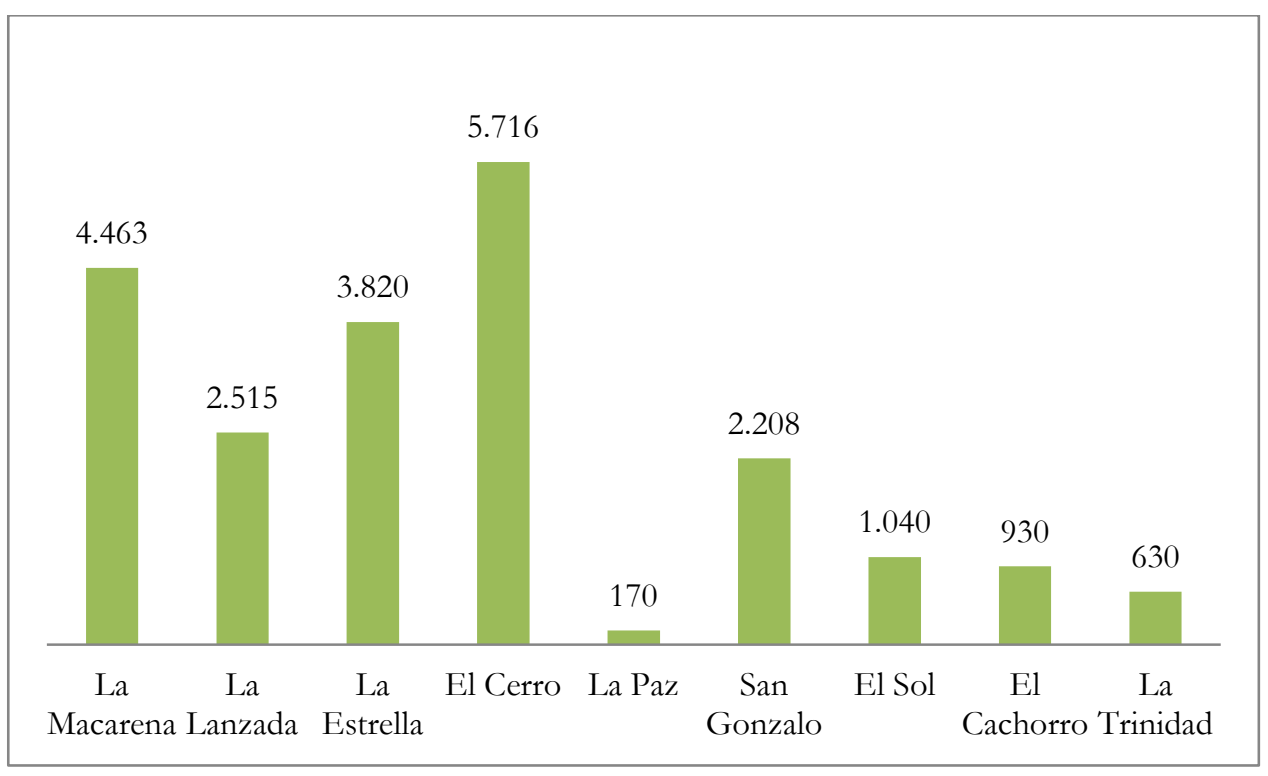

Fuente: Elaboración propia

A las Hermandades les ha costado bastante llegar a Twitter, no obstante, cada vez son más las corporaciones que usan esta red social para abrir sus Casas de Hermandad al mundo y ofrecer una nueva vía de comunicación adaptada a los tiempos. Caso distinto es el uso que éstas realizan de la red social Facebook. Pese a que el $63 \%$ tiene página propia, la mayoría posee un perfil programado para publicar el mismo contenido que tuitean, de forma, que usan esta red como un simple tablón de anuncios. De hecho, son pocos los casos en los que se utiliza Facebook para publicar contenidos de una forma más extensa y periodística de lo que permite Twitter (recordemos su limitación de 140 caracteres), en estos casos, las noticias suelen ser un calco de las aparecidas en los boletines digitales de la Hermandad.

En términos porcentuales, el $70 \%$ de las Hermandades utiliza Facebook como un espejo de Twitter (Ver Gráfico 8), es decir, no genera contenidos específicos para esta red, el 7\% apenas actualiza noticias, tal es el caso de La Carretería, Cristo de Burgos o San Benito y un 13\%, entre los que se encuentra San Gonzalo, Pino Montano y Los Panaderos, no publica nada (Ver Gráfico 9).

El tono del lenguaje empleado, tal y como ocurre en Twitter, es formal, sin embargo, el flujo comunicativo es claramente descendente, siendo muy escasos los comentarios publicados por sus seguidores.

Gráfico 8: Porcentaje de Hermandades con presencia en Facebook 


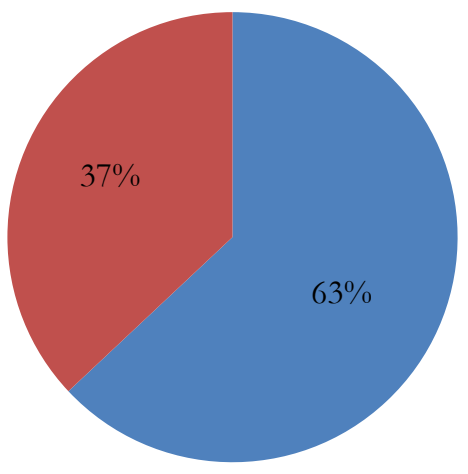

- HERMANDADES CON FACEBOOK

- HERMANDADES SIN FACEBOOK

Fuente: Elaboración propia

Gráfico 9: Actividad comunicativa de las Hermandades en Facebook

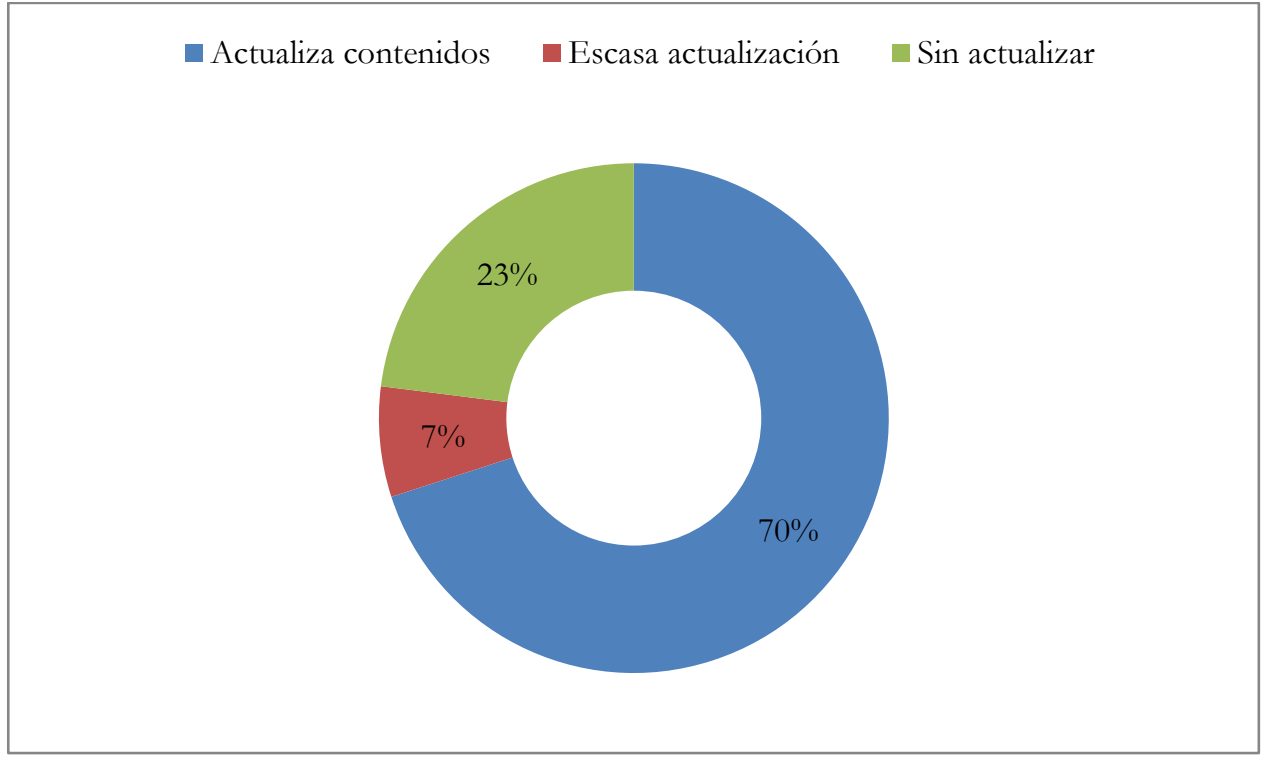

Fuente: Elaboración propia

Otro aspecto a destacar es que las Hermandades poseen un número ínfimo de seguidores en Facebook, al tiempo que no registran el número de fans, con lo cual es casi imposible realizar una medición a nivel cuantitativo. Además, a diferencia de Twitter, no todas poseen una cuenta oficial. Por jornadas, los días en los que se registra un mayor número de Hermandades con perfil en Facebook 
son Martes Santo (88\%), Miércoles Santo (78\%) y Lunes Santo (67\%). Por el contrario, el Jueves Santo, tal y como ocurría en Twitter, es el día con menor número de Hermandades presentes en esta red social, un 43\% (Ver Tabla 4).

Tabla 4: Presencia de las Hermandades en Facebook por días

\begin{tabular}{|l|r|}
\hline PREVIO & $44 \%$ \\
\hline DOMINGO DE RAMOS & $63 \%$ \\
\hline LUNES SANTO & $67 \%$ \\
\hline & $88 \%$ \\
\hline MIÉRCOLES SANTO & $78 \%$ \\
\hline JUEVES SANTO & $43 \%$ \\
\hline MADRUGÁ & $50 \%$ \\
\hline VIERNES SANTO & $57 \%$ \\
\hline SÁBADO SANTO & $60 \%$ \\
\hline DOMINGO DE & $100 \%$ \\
\hline RESURRECCIÓN & \\
\hline
\end{tabular}

Fuente: Elaboración propia

De igual forma, es interesante reseñar la existencia de tres cuentas no oficiales de Hermandades que no tienen presencia oficial en Facebook. Se trata de las Hermandades de La Cena y Jesús Despojado, ambas del Domingo de Ramos, y de la Hermandad de San Esteban, del Martes Santo.

Asimismo, de entre todas las que poseen cuenta en esta red social sólo una, Santa Genoveva, posee una página con perfil de empresa en vez de un perfil personal, lo que le permite un mejor posicionamiento en los buscadores, mayor visibilidad y por supuesto estadísticas sobre su impacto, interacción, seguidores, etc.

\subsection{Las redes sociales como fuentes informativas}

Las redes sociales se han convertido en una excelente fuente de noticias para los medios de comunicación, los cuales no dudan en acudir a ellas para estar constantemente actualizados respecto a sus temas de interés y, en este sentido, las Hermandades de Semana Santa no son una excepción, de forma que su presencia en la Red se ha convertido en una fuente informativa más para los medios que se ocupan de la Información Cofrade, aunque no la única, ya que el 
contacto directo con los miembros de la corporación continúa siendo la piedra angular sobre la que se cimenta este tipo de noticias.

'El Llamador' de Canal Sur es el medio que mayor uso informativo otorga a Twitter. Con más de 60.000 seguidores, @elllamadorcsr posee un perfil muy activo cuyo 'time line' está repleto de retweets de las noticias publicadas por las distintas Hermandades, pero también de los reportajes y noticias publicadas por "Pasión en Sevilla" (http://sevilla.abc.es/pasionensevilla/).

La web especializada en información cofrade de $A B C$ de Sevilla también se nutre de las informaciones publicadas en las redes sociales para mantener al día sus secciones de Eventos, Noticias y Actualidad, las cuales enlazan directamente con el Twitter de las distintas Hermandades, siendo frecuente que se las cite como fuentes informativas siguiendo la fórmula "según informa en su Twitter..." o "según publica en su página web...".

'Pasión en Sevilla' cuenta con casi 38.000 seguidores en Twitter (@pasionensevilla) donde desde abril de 2009 ha generado más de 10.000 tweets. La publicación mantiene una comunicación bastante activa con las distintas Hermandades de Penitencia y el Consejo de Cofradías (@BoletinCofradia).

Una forma similar de proceder es la que sigue Diario de Sevilla en su apartado de Cofradías (www.diariodesevilla.es/cofradias) y en 'CofradíasDdS' el tablón que sobre la actualidad cofrade posee este diario en las redes sociales. De reciente creación (9 abril de 2014), cuenta con cuatrocientos seguidores en Facebook (https://www.facebook.com/cofradiasdds) y 8.400 en Twitter (@Cofradias_DdS). Desde 2012 ha generado más de dos millares de tweets, así como numerosos retweets de las noticias publicadas por las Hermandades, pero siempre con una peculiaridad: que estén relacionadas con las noticias que ellos mismos generan y publican en su web.

Con más de 18.000 seguidores, @LaPasiónCTV es la cuenta del programa 'La Pasión No Acaba', el programa que todos los martes se encarga de la actualidad cofrade en El Correo TV y que tiene una gran actividad, como atestiguan los casi 13.000 tweets que han publicado, entre los que abundan numerosos vídeos y retweets de las noticias generadas por las Hermandades de Penitencia de Sevilla.

Esta misma información, pero a menor nivel, también se aprecia en http://elcorreoweb.es/semanasanta/ y en @MP7EICorreo, la cuenta en Twitter de la revista 'Más Pasión' de @elcorreoweb y que, con más de siete años de vida, se publica el primer domingo de cada mes. @MP7EICorreo tiene 2.997 seguidores y su actividad se centra en el retweet de actos, noticias y agenda de las distintas 
Hermandades, así como links a los distintos reportajes y contenidos de la publicación en papel.

Por último, encontramos la web Arte Sacro (http://www.artesacro.org/), uno de los medios online de referencia en el ámbito de la Información Cofrade, que se nutre principalmente de comunicados y notas de prensa a la hora de actualizar su site. Su perfil en Twitter (@ArtesacroT) es bastante activo a nivel de retweets generados por las distintas Hermandades como evidencian sus casi 12.000 tweets, entre los que también es frecuente encontrar retuiteados los comentarios que los usuarios, en general, realizan al paso de cada cofradía o las imágenes que suben con sus smartphones a las redes sociales.

Esta misma tónica la encontramos en la radio online La Saeta que emite información cofrade las 24 horas. @Isaeta tiene más de 8.000 seguidores y casi 30.000 tweets publicados, lo que supone una alta frecuencia de publicación.

Son escasos los retweets, pero si muy frecuentes la mención de las cuentas de Twitter de las distintas Hermandades en sus publicaciones, así como el uso de sus fotografías y la publicación de enlaces a las noticias que aparecen en los perfiles de Facebook de las mismas, lo cual nos indica claramente que se nutre a nivel informativo de las webs y redes sociales de las distintas Cofradías, de hecho, son abundantes las noticias relativas a las vidas de las Hermandades, como pueden ser los acuerdos llegados por las distintas juntas de hermanos, o el fallecimiento de un determinado miembro.

Un caso excepcional a nivel radiofónico es el del programa 'Cruz de Guía' de Radio Sevilla que, con 3.370 seguidores en Twitter (@cruzdeguiaser) y pese a ser seguidor de todas las Cofradías hispalenses, no presenta entre sus publicaciones retweets de las Hermandades o de sus juntas directivas, de hecho casi todos sus tweets son de producción propia y hacen referencia a cruzdeguia.tv, donde se pueden encontrar desde vídeos de las procesiones a artículos publicados en el apartado de noticias locales de la Cadena Ser y al player radio de la misma, donde se pueden escuchar marchas procesionales (http://www.cadenaser.com/player radio.html?canal=SEVI).

\section{Conclusiones}

La lectura transversal de los dos ejes de estudio de la investigación nos permite concluir la visión hipotética formulada al principio de este documento, que la presencia en las redes sociales permite a las Hermandades de Semana Santa de Sevilla enfrentarse al reto de interactuar con sus usuarios, generar una 
comunidad de marca, incrementar su notoriedad y reforzar su posicionamiento comunicativo de cara a los medios de comunicación.

Las Hermandades y Cofradías de Penitencia de Sevilla son conscientes del potencial comunicativo que ofrece Internet y están incrementando su presencia en las redes sociales a fin de mejorar de forma sustancial la manera en la que se comunican con sus hermanos y la sociedad en general, pero también con un público externo que está constituido por los medios de comunicación, los cuales utilizan estas plataformas a modo de fuentes informativas.

Sus páginas webs se erigen en una herramienta primordial de comunicación ya que permiten un contacto directo con los hermanos a nivel informativo que se refuerza con el envío de boletines digitales, al tiempo que facilitan las gestiones de la Hermandad gracias a una serie de servicios online como son la posibilidad de sacar la papeleta de sitio o realizar gestiones administrativas.

A nivel de redes sociales, las Cofradías hispalenses han intensificado su presencia en Twitter. La red de microblogging es la preferida por el $65 \%$ de las Hermandades para transmitir noticias sobre sus cultos, resolver dudas, retuitear fotos o responder a sus hermanos, habiendo experimentado un crecimiento cercano al $12 \%$ durante el pasado año. Como media, las Cofradías más activas son capaces de publicar una cuarentena de informaciones semanales entre las que destacan las noticias relativas a la vida de Hermandad en un $45 \%$, siguiéndole a bastante distancia Evangelios (17\%) y Cultos (16\%).

El número de tweets se dispara durante Semana Santa, llegando incluso a superar la centena el día que realizan la Estación de Penitencia, lo mismo ocurre con los retweets, que se cuentan por miles, y apuntan a un aprovechamiento de la potencialidad proactiva de los mensajes de Twitter, ya que la mayoría de las Hermandades ha sabido crear una cadena de enlace de redes que posibilita la difusión de sus mensajes con una dinámica parecida al marketing viral, es decir, una difusión que sigue el esquema de ramificación arbórea. El elevado número de retweets registrados multiplica exponencialmente la creación de intersecciones y canales de distribución de sus noticias.

El nivel de hipertextualidad de las publicaciones es medio, lo que apunta a un intento de las Hermandades por hacer uso de las potencialidades interactivas de la red analizada. La mayoría de los enlaces a los que vinculan los tweets analizados son sitios web y vídeos colgados en la plataforma YouTube.

En el caso de Facebook, y pese a que el 62\% tiene página en esta red social, la presencia de las Hermandades en muchas ocasiones es meramente testimonial y en aquellas que mantienen sus cuentas activas observamos escasas publicaciones de contenido, un flujo comunicativo descendente, escasa 
bidireccionalidad, así como un cuerpo textual más extenso y periodístico, pese a que en la mayoría de las ocasiones no deja de ser un fiel espejo de lo ya publicado en Twitter. Todo ello apunta a un desaprovechamiento de las potencialidades comunicativas de esta red social, que es utilizada para difundir más que para comunicar.

A nivel periodístico, las redes sociales se han convertido en una excelente fuente informativa para los medios encargados de cubrir la Información Cofrade. Las ediciones digitales que sobre este tema publican los medios hispalenses y las webs temáticas dan buena cuenta de la actividad generada por las Hermandades en las redes sociales y les sirve, fundamentalmente, para actualizar los apartados de Eventos y Noticias que todas ellas poseen, así como para mantener un alto nivel informativo en las cuentas que todos estos medios poseen en la red social Twitter, donde es frecuente encontrar un elevado porcentaje de retweets de los actos, noticias y agenda de las distintas Cofradías.

No obstante, pese a ser una manera rápida y fiable de estar constantemente actualizados sobre la vida de las distintas Cofradías, su valor como fuente informativa es relativo por incipiente y novedoso, siendo el contacto directo con los miembros de las distintas corporaciones la piedra angular sobre la que aún se sustenta la Información Cofrade en general.

\section{Bibliografía}

Abc. (2014): “¿Cuántos hermanos "tuiteros” tienen las Cofradías de Sevilla?”, en Abc, consultado el 12 de abril de 2014 desde: http://sevilla.Abc.es/pasionensevilla/index.php?option=com content\&view=articl e\&id=24977\&Itemid=182\#.UuDs0Wct0zl. Twitter

Abc. (2013): "La Semana Santa se reinventa en Internet", en ABC, consultado el 12 de abril de 2014 desde: http://www.Abc.es/tecnologia/redes/20130324/Abcisemana-santa-reinventa-internet-201303221823.html

Aimc. (2014): "Resumen general de resultados EGM. Febrero 2014". Disponible en: www.aimc.es/-Datos-EGM-Resumen-General-.html.

Armañanzas E.; Díaz Nosty J y Messo-Ayerdi, K. (1996): El periodismo electrónico. Información y servicio multimedia en la era del ciberespacio. Barcelona: Ariel Comunicación.

Berelson, B. (1952). Content Analysis in Communications Research. Nueva York: Free Press. 
Cebrián Herreros, M. (2008): "La Web 2.0 como red social de comunicación e información", Estudios del Mensaje Periodístico, 14, pp. 345-361 (DOI: http://dx.doi.org/10.3916/c33-2008-02-001).

Comscore. (2014): "Resumen del uso de internet en España mes a mes". Disponible

en: https://www.comscore.com/esl/Panorama Digital/Datos actuales

Creswell, J.W. y Plano, V. (2011). Designing and Conducting Mixed Methods Research. Thousand Oaks: Sage Publications.

De Haro de San Mateo, V.; Grandío Pérez, M.M. y Hernández Pérez, M. (2013): Historias en red: impacto de las redes sociales en los procesos de comunicación. Murcia: Universidad de Murcia.

El Correo TV. (2014): "Disfruta de toda la Semana Santa de Sevilla 2014 en directo en El Correo TV". Disponible en: http://elcorreoweb.es/2014/03/26/disfruta-de-toda-la-semana-santa-2014-endirecto-en-el-correo-tv/

El Mundo. (2011): "El creador del concepto 'Web 2.0' asegura que a pesar de su éxito 'está obsoleto"'. Disponible en: http://www.elmundo.es/elmundo/2011/11/22/navegante/1321978250.html

Europa Press. (2013): "La penetración de usuarios de Internet móvil en España alcanza el $84 \%$ en 2013". Disponible en: http://www.europapress.es/portaltic/internet/noticia-penetracion-usuariosinternet-movil-espana-alcanza-84-2013-20131219120549.html.

Europa Press. (2013): "El Ayuntamiento de Sevilla presenta una aplicación para seguir la Semana Santa". Disponible en: http://www.europapress.es/portaltic/movilidad/software/noticia-ayuntamientosevilla-presenta-aplicacion-seguir-semana-santa-20120326190831.html

Evonova. (2013): "Semana Santa y Social Media: las Hermandades de Sevilla en redes sociales". Disponible en: http://evonova.es/semana-santa-y-social-medialas-Hermandades-de-sevilla-en-redes-sociales/

Farias-Batle, P. (2000): Empresa informativa. Proyecto docente inédito. Málaga: Universidad de Málaga.

Fernández, M.J, y Paniagua, F.J. (2014). El poder de las redes sociales en la política y en los movimientos sociales. En AA.VV, Gestión política, campañas y nuevas tecnologías (pp.2-26). Murcia: Asociación Latinoamericana de Investigadores en Campañas Electorales. 
Fotonostra (2012): "Redes sociales". Disponible en: http://www.fotonostra.com/digital/redesociales.htm

Fresneda Fuentes, S. (2008). La gestión de los bienes histórico-artísticos. En Vázquez Bermúdez, I. y Díaz Fernández, M.C., Investigaciones turísticas. Una perspectiva multidisciplinar. Sevilla: Universidad de Sevilla.

Fundación Telefónica (2015): "La Sociedad de la Información en España". Disponible en: http://www.fundaciontelefonica.com/2015/01/21/sie14-informesociedad-informacion-espana-pais-conectado-europa/

García Estévez, N. (2012), Redes Sociales en Internet. Implicaciones y consecuencias de las plataformas 2.0 en la sociedad. Sevilla: Editorial Universitas.

García-Jiménez, A. y Rupérez-Rubio, P. (2007): Aproximaciones al periodismo digital. Madrid: Editorial Dykinson.

Giralda Tv. (2012): "Semana Santa 2012. Informe de resultados. Estadísticas". Disponible en: http://www.giraldatv.com.es/web/wpcontent/uploads/2013/02/INFORME-ESTADISTICO-RESULTADOS-\%C2\%B7SEMANA-SANTA-2012-EN-GIRALDATV.pdf

Hermandades de Sevilla. (2014): "Las Cofradías de Semana Santa o de Pasión". Disponible en: http://www.hermandades-de-sevilla.org/hermandades/historiade-las-hermandades-y-cofradia/las-cofradias-de-semana-santa-o-de-pasion

Horasur. (2013): "Los medios le llevan la Semana Santa a todos los rincones". Disponible en: http://www.horasurdigital.com/2013/03/29/los-medios-le-llevanla-semana-santa-a-todos-los-rincones/

Ideae. (2012): "La Semana Santa de Sevilla en tu bolsillo". Disponible en http://www.ideae.net/contenidos/la-semana-santa-de-sevilla-en-tu-bolsillo/

Jiménez Sampedro, R. (2011): Sevilla en sus Cofradías. Sevilla: Abec Editores.

Krippendorf, K. (1990). Metodología de análisis de contenido. Teoría y práctica. Barcelona: Paidós

Medios Sociales. (2011): "La Semana Santa también es 2.0". Disponible en: http://mediossociales.es/semanasantaredessociales/

Núñez Gómez, P.; García Guardia, M. L. y Hermida Ayala, L. (2012): Tendencias de las relaciones sociales e interpersonales de los nativos digitales. Revista Latina de Comunicación Social, 67, pp. 179-202. 
Sánchez Gonzales, H. M. y García Estévez, N. (2010): Las redes sociales, la información emotiva y la participación especializada. En AA.VV., Internet Como Fuente Generadora de Contenidos Especializados (pp.371-387). Barcelona: Universitat Pompeu Fabra.

O'Reilly, T, y Batelle, J. (2009): "Web Squared: Web 2.0 Five Years On”. Disponible en: http://assets.en.oreilly.com/1/event/28/web2009 websquaredwhitepaper.pdf

Parejo, J. (2012): “Las Cofradías se apuntan al 2.0". Disponible en: http://www.diariodesevilla.es/article/cofradias/1225576/las/cofradias/se/apuntan .html\#sSf3G4y1PEaTcyTg

Sevilla Directo. (2014): "Este martes se presenta la primera revista de Cofradías y redes sociales). Disponible en: http://sevilladirecto.com/este-martes-sepresenta-la-primera-revista-de-cofradias-y-redes-sociales/

Solis, B. (2011): Engage!: The Complete Guide for Brands and Businesses to Build, Cultivate, and Measure Success in the New Web. Kindle Edition.

Luengo Mena, J. (2013): Liturgia, Culto y Cofradías. Sevilla: Abec Editores.

Zona Digital. (2012): "Una aplicación para seguir la Semana Santa con tu Smartphone". Disponible en: http://zonadigital.excite.es/aplicacion-semanasanta.html

\section{Forma de citar este artículo en bibliografías}

ALONSO GONZÁLEZ, Marián (2015): "Hermandades de Semana Santa y redes sociales. Las nuevas tecnologías al servicio de la Información Cofrade", en Revista PANGEA, 6, páginas 104 a 135. Red Académica Iberoamericana de Comunicación. Recuperado el _ de __ de 2___ de: http://www.revistapangea.org 